$\stackrel{N / 2}{N}$

Global Journals Inc

(8)

\title{
Smart Agri-Preneurship Dimensions and Food Affordability
}

\author{
By Omodanisi, E. O., Egwakhe, A. J. Ajike, O. E.
}

Abstract- This research sought to investigate the effect of smart Agri-preneurship dimensions on food affordability in South-West, Nigeria. Diverse literature confirmed positions of scholarly discourse regarding the relationship between smart Agri-preneurship dimensions and food affordability. Cross-sectional research design was adopted while adopted questionnaire was used to source primary data. Duly registered Agri-preneurs in South-West Nigeria were selected with a population of $(2,557)$. Cochran, Hatzes, Butler, and Marcy formula (1997) was adopted and a reliable and valid questionnaire was tested on 558Agri-preneurs. The regressed constructs revealed a positive and significant effect of smart Agri-preneurship on food affordability. The findings indicated that smart Agri-preneurship dimensions have positive and significant effect on food affordability (Adj. R2 $=0.602, F(6,551)=141.319, p=0.000)$. The study concludes that farmers should embrace smart Agri-preneurial technologies as innovations that could improve their farm yields, hence reduce the cost of production and make food output more affordable. The study recommends that the government should engage Agri-preneurs and provide partnerships that would be beneficial in improving food affordability opportunities through the adoption of smart technologies.

Keywords: farm yield, food affordability, food sustainability, smart agri-preneurship.

GJMBR-A Classification: JEL Code: M10

Strictly as per the compliance and regulations of:

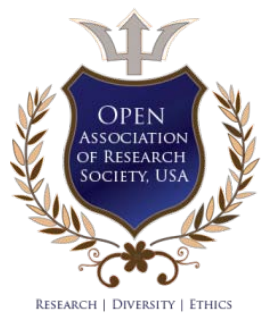

(C) 2020. Omodanisi, E. O., Egwakhe, A. J. Ajike, O. E.. This is a research/review paper, distributed under the terms of the Creative Commons Attribution-Noncommercial 3.0 Unported License http://creativecommons.org/licenses/by-nc/3.0/), permitting all non-commercial use, distribution, and reproduction in any medium, provided the original work is properly cited. 


\title{
Smart Agri-Preneurship Dimensions and Food Affordability
}

\author{
Omodanisi, E. O. ${ }^{\alpha}$, Egwakhe, A. J. ${ }^{\circ}$ \& Ajike, O. E. ${ }^{\circ}$
}

Abstract- This research sought to investigate the effect of smart Agri-preneurship dimensions on food affordability in South-West, Nigeria. Diverse literature confirmed positions of scholarly discourse regarding the relationship between smart Agri-preneurship dimensions and food affordability. Crosssectional research design was adopted while adopted questionnaire was used to source primary data. Duly registered Agri-preneurs in South-West Nigeria were selected with a population of $(2,557)$. Cochran, Hatzes, Butler, and Marcy formula (1997) was adopted and a reliable and valid questionnaire was tested on 558Agri-preneurs. The regressed constructs revealed a positive and significant effect of smart Agri-preneurship on food affordability. The findings indicated that smart Agri-preneurship dimensions have positive and significant effect on food affordability (Adj. $R^{2}=0.602, F$ $(6,551)=141.319, p=0.000)$. The study concludes that farmers should embrace smart Agri-preneurial technologies as innovations that could improve their farm yields, hence reduce the cost of production and make food output more affordable. The study recommends that the government should engage Agri-preneurs and provide partnerships that would be beneficial in improving food affordability opportunities through the adoption of smart technologies.

Keywords: farm yield, food affordability, food sustainability, smart agri-preneurship.

\section{INTRODUCTION}

F ood affordability globally has become a rising concern as poverty and hunger enthralls millions. This seems to be causing a more elusive ideology about the possible fastest end to starvation especially, in developing nations. Although the nature and depth of food insecurity have generated multidimensional approaches to hunger and food sourcing, its availability is not the same as food affordability. The kind of food households can afford relatively depends on the budget of the household and the local price of the food (Drewnowski, 2020). According to Lauri, Palak, and Kumiko (2018), across Africa, almost half of all spending on household budgets is based on food affordability, with the highest-burden falling on low-income households. In Nigeria, there has been a worrisome trend that reveals the country to be extremely poor, with a forecast position from the report of Gates foundation (2019) as the likely poverty capital of the world by 2030 .

Furthermore, a growth trend has been observed in pricing of crops produced in Nigeria from N14.86bn in

Author a $\sigma \rho$ : Department of Business Administration and Marketing, Babcock University, llishan-Remo, Ogun State, Nigeria.

e-mails: smartagripreneurship@gmail.com, jj.adeyinka@gmail.com
2013, N7.18bn in 2015 and N21.09bn in 2017 as stated by the Nigerian Bureau of Statistics (Adelowokan, Maku, Babasanya \& Adesoye, 2019), revealing the expensive nature of home-grown foods within the country, and making affordability an illusion. This is further heightened by the on-going quarrel between the Miyetti Allah Cattle herders and farmers, causing loss of farm produce, resulting in artificial scarcity and making food affordability an impossible milestone to achieve shortly. Established literature (Aatif, Kaiser, Showket, Prasanto, \& Negi, 2018; Clapp, Newell \& Brent, 2018; Kropff, Pilgrim \& Neate, 2019; Labya, Megha, \& Kamlesh, 2018) have earlier investigated the link between smart Agripreneurship, nutrient cycling, soil analysis, and greenhouse farming, individually, on reduced cost of food in developed economies. However, a gap in knowledge exists on the nexus between smart Agripreneurship dimensions (hydroponics, geo-mapping, greenhouse farming, drone agriculture, nutrient cycling, and soil analysis) and food affordability in developing economies as posited by Solomon, Mungai, and Radeny (2012), Sayem (2017) and Wekesa, Ayuya, and Lagat (2018), especially from the Nigerian context.

Scholars (Fasiha, Kaleem, Aleem, \& Shujjah, 2017; Vox, Loisi, Blanco, Mugnozza, \& Schettini, 2016; Yi-Hsuan, Ssu-Pei, \& Ting, 2019) had confirmed positive and significant relations between smart Agri-preneurship measures and food affordability, as food availability became excess hence driving down the cost of crops produced. This work sought to investigate the effect of smart Agri-preneurship dimensions on food affordability from the Nigerian context. The contributions from this study would help to provide a framework upon which smart agri-preneurial measures can be adopted as well as provide veritable empirical contributions to literature. The work has been structured as follows: Introduction, Literature review, methodology, results and discussions, and then conclusions.

\section{il. Literature Review - Smart Agri- Preneurship}

The smart Agri-preneurship concept is an amalgamation of three independent ideologies - smart technology, agricultural business, and entrepreneurship. Smart technology refers to the scientific methods, structures, and devices that aid data tracking, improve efficiency, and ecologically accommodating (Osabohien, Osabuohien, \& Urhie, 2018). Indeed, it is a 
productivity enhancement method that adopts innovative and technological approaches (Uche \& Familusi (2018). Chait (2014) and David (2016) explained agribusinesses as businesses related to agriculture yet comprising of the processors, warehouses, wholesalers, and retailers, with a focus on size, excluding small business operations such as family farms. Cains and Henshel (2019) defined the agribusiness as a large scale business operation, consisting of the whole gamut of agricultural production, processing and distribution of products and the assembly of farm machinery and supplies. Entrepreneurship in agriculture, as described by Paul, Amarachi, Oyedele, Odafe, and Juliana (2018), is the creation of an innovative economic organization for gains using inherent unique leadership and managerial skills, under certain risk conditions.

However, Rehman and Shaikh (2014) posited that smart Agri-preneurship is an approach which pools technology and entrepreneurial ideologies in agricultural business for growth purpose within a climate-friendly environment. Uche and Familusi (2018) also portrayed smart Agri-preneurship as the profitable union of agriculture, technology, and entrepreneurship to turn farms into successful agribusinesses. This concept has been beneficial in improving farm yields and making the food more available hence rubbing off on food affordability and overall sustainability over time. It has been seen to make foods that have cyclical growths more readily available irrespective of the time of the year, especially when hydroponics is adopted. Various other smart agri-preneurial procedures such as drone programming aid better visibility of the large farm areas, while geo-mapping makes data more available for the guidance of improvement methods. Although there are so many smart agri-preneurial dimensions, this study focused on greenhouse farming, hydroponics, geomapping, drone agriculture, nutrient cycling, and soil analysis.

\section{ili. FOOD AfFordability}

Wright, Gupta, and Yoshihara (2018) explained food affordability as the cost of a household's food supply relative to the income earned by it. They explained that the notion of affordability from the context of the ability to financially fend for food preferences and needs by a country (macro-level) or a household on a unit basis (Wright et al., 2018). Achim, Robert, Robert, and Nina (2017) suggested that the affordability of food is dependent on food cost and availability of disposable income for food purchases. According to Gasparatos et al. (2017), the food affordability index is a measure of the income effect, or the consumption changes arising from changes in real incomes or of food prices. Lauri, Palak, and Kumiko (2018) looked into products and services across Africa, from the dimension of affordability of food and household budgets, observing it accounted for almost half of all spending in many developing nations, with the highest-burden falling on low-income households. Enhancing the affordability of food spending, therefore, presents a huge opportunity to create budgetary space at a household level, freeing up buying power to be spent on more food, more nutritious food, or elsewhere entirely.

Browne (2018) identified the principal issues related to food affordability as being the price of food which smart Agri-preneurs use as a market entry advantage, targeting those on low incomes who feel they cannot afford to eat balanced diets. The price of healthy food items is very variable in developing economies, with a tendency for price to be lower in larger agribusinesses and areas with low levels of social and economic deprivation. Food may be available but not affordable, presupposing access to sufficient food while quality, safety, and nutritional integrity of food to a specific population should be observed pricewise (Lauri et al., 2018). People with limited access to affordable food have shown to have higher rates of obesity and obesity-related and chronic diseases (Lauri et al., 2018). However, it can be viewed that food affordability is subject to food accessibility, availability, and all the mechanisms targeted at allocation of food as well as all the food preferences.

\section{iV. Smart Agri-Preneurship Dimensions AND FOOD AfFordability}

The nexus between smart Agri-preneurship and food affordability anchored on the Lewis theory propounded by W. Arthur Lewis in 1954. It focused on subsistence economy two-sector model. The first sector is a traditional, overpopulated rural subsistence sector characterized by zero marginal labour productivity - a situation which Lewis model classifies as surplus labour in the sense that it could be withdrawn from the traditional agricultural sector without any loss of output (Lewis, 1954). The second sector, which he refers to as the capitalist sector may be private or public. The use of capital is controlled by the capitalists, who hire the services of labour. It includes manufacturing, plantations, mines, and virgin markets.

Empirical literature (Currey, Walters, \& Flax, 2019; Zaccardelli, Pane, Villecco, Palese \& Celano, 2018; Brück, Naudé, \& Verwimp, 2011) revealed that smart Agri-preneurship significantly reduced cost of farm produce hence improving food availability. Their findings confirmed that south Agri-preneurship induced innovation as bio-stimulant effects were observed on the plants, as improved efficient use of the farm inputs and production. Similar studies by Vox, Teitel, Pardossi, Minuto, Tinivella and Schettini (2010), Santeramo (2015), Hubeau, March and, Coteur, Mondelaers, Debruyne, and Van-Huylenbroeck, (2017) and Velde and Nisini 
(2019) that operated modern greenhouses and utilized other smart Agri-preneurship measures observed positive and significant enhancement of optimization of farm land which resulted in increased farm output and affordability of farm products. In a similar study carried out by Anderson (2014), findings revealed that drone agriculture enhanced early discovery of pest and disease on farm land, as well as improved geographical analysis and coverage, which significantly increased farm output and overall yield performance. The improvement experienced in farm yield spilled over influencing the pricing of food produce, hence making food more readily affordable.

Other scholars such as Alston, Beddow, and Pardey (2009), Wiebe (2003), Barwa (2014), Clark, Rouse, Sehgal, Bailey, Bell, Pike, Sharpe and Freedman (2019), Gupta and Kaushal (2018) that empirically investigated how smart Agri-preneurship affected food affordability with measures such as agriculture output cost of production and farm productivity, posited that stress on farmers and cost of production dropped significantly, and a subsequent resultant increase in consumers' affordability of farm produce was observed. The empirical studies of Labya et al. (2018), Nisha, Somen, Kaushal, Narendra and Chaurasia (2018), and Sarah (2019) found that a positive and significant relationship between hydroponic processes and food affordability, as they observed that access to water had the greatest effect on the urban hydroponic farming, followed by access to capital. They posited that the hydroponic industry is expected to grow exponentially due to the worsening soil conditions. Emphasis was placed on countries with high demand for premium vegetables that suffer urban concrete conglomeration; the embracing of soil-less would be used to improve farm yield, food quality, and food affordability. There are other studies (Zamora-Izquierdo, Santa, Martínez, Martinez, and Skarmeta (2019) and Pack and Mehta (2012), that have established empirical recognition for greenhouse technology as akey to sustainable crop production and food affordability as it serves in providing growth in farm productivity. Furthermore, Psirofonia, Samaritakis, Eliopoulos, and Potamitis (2017) and Torres (2017) revealed that proper management of greenhouses farming increased consumers' food affordability and crop output from respective studies.

Despite these positive observations, some scholars (Dauphin, Lubroth \& Jobre, 2016; Fernando \& Merino, 2012; Wongkiew, Park, Chandran, \& Khanal, 2018) refuted this trend of growing influence of smart Agri-preneurship on food affordability. Dauphin, Lubroth, and Jobre (2016) established from their study that smart agri-technology is either very expensive for local growers/farmers to afford or even not available which resultsin increased cost of farm procedures, farm output decline, and unaffordable farm produce. Similarly, Fernando and Merino (2012) and Wongkiew, Park,
Chandran and Khanal (2018) established that despite the maximum efficiency observed in the adoption of hydroponic system, as little resources were required and fast yield of produce could be achieved, the farm output remained small as the controlled environment was incapable of producing large farm output, hence leaving the scarce produce becoming expensive, as such less affordable to consumers, especially in the developing countries.

\section{Methodology}

This cross-sectional survey sought to investigate smart Agri-preneurship dimensions on food affordability in South-West, Nigeria. The selection of South West Nigeria which consists of Lagos, Ogun, Ekiti, Osun, Oyo, and Ondo States, is based on the relative peace within this geopolitical region, as well as the fact that it has the highest number of people population-wise after only the North West Nigeria (World Population Prospect - WPP, 2019). The researcher delineated the North West despite it being the most populous region because of the large number of internally displaced persons (IDPs) and inherent security challenges. The study's population is two thousand, five hundred and fifty-seven $(2,557)$, which are the duly registered agri-prenuers in the region, as provided by the Ministry of Agriculture of the respective states as at 31st December 2018. However, adopting the Cochran, Hatzes, Butler and Marcy formula (1997) of sample size formula, a sample size of 486 was determined with $\mathrm{N}$ (the population size) $=2,557 ; \mathrm{Z}(95 \%$ confidence interval $)=1.96 ; P(5 \%$ error term $)=0.5 ; q=1-p ; d$ (degree of accuracy) $=0.04$.

$$
\begin{gathered}
n=\frac{2,557(1.96) 2(0.5)(0.5)}{(0.04) 2(2557-1)+(1.96) 2(0.5)(0.5)} \\
n=486
\end{gathered}
$$

Based on the attitude of respondents and as recommended by Zikmund, Babin, Carr, and Griffin (2010), the sample size becomes 632 was adopted for the study through the addition of $30 \%$ of the calculated sample $(486+146=632)$ to make up for nonresponse issues as well as compensate for errors and omissions in questionnaire response.

The study utilized primary data collected with a structured questionnaire adapted from extant literature as follows: Green housing (Al-Houti, 2017; Manohar, \& Igatidnathane, 2007); Hydroponics (Kaur, 2017; Kibiti \& Gitonga, 2017; Sardare \& Admane, 2015); Geomapping (Harrell, 2014; Yliskylä-Peu+ralahti, 2014); Drone agriculture (Al-Arab, Torres-Rua, Ticlavilca, Jensen, \& Mc Kee, 2013; Hafsal, 2016); and Soil analysis (Gordon, 2004; Pettersen, 2014) and Food affordability (Capone, El Bilali, Debs, Cardone, \& Driouech, 2014; Mansour, 2014). A pre-test was undertaken in selected farms within the North central 
area of Nigeria, covering Kwara and Benue States, to confirm the reliability and validity of the research instrument. The results of the scientific validity and reliability tests carried out are as stated in Table 1.

Table 1: Pilot study results - Validity and Reliability Results

\begin{tabular}{|c|c|c|c|c|c|c|}
\hline Variable & $\begin{array}{c}\text { Number } \\
\text { of Items }\end{array}$ & AVE & KMO & $\begin{array}{c}\text { Bartlett's test } \\
\text { of Sphericity }\end{array}$ & $\begin{array}{c}\text { Sig for KMO \& } \\
\text { Bartlett's Test }\end{array}$ & $\begin{array}{c}\text { Cronbach's } \\
\text { Alpha }\end{array}$ \\
\hline Green housing & 6 & 0.672 & 0.559 & 26.709 & 0.03 & 0.731 \\
\hline Hydroponics & 6 & 0.619 & 0.698 & 21.785 & 0.00 & 0.821 \\
\hline Geo-mapping & 6 & 0.532 & 0.636 & 28.573 & 0.01 & 0.861 \\
\hline Drone Agriculture & 6 & 0.763 & 0.791 & 23.220 & 0.01 & 0.773 \\
\hline Soil analysis & 6 & 0.781 & 0.688 & 29.368 & 0.01 & 0.658 \\
\hline Food affordability & 6 & 0.792 & 0.750 & 46.811 & 0.00 & 0.805 \\
\hline
\end{tabular}

Source: SPSS Result Computation (2020)

The collected data was analysed using the ordinary least square method of analysis (linear multiple regression analysis) after being subjected to data treatment in compliance with the main assumptions of regression (normality, heteroscedasticity, linearity, and multi-collinearity), and found to be free from errors. The structured equation of the study is as follows:

$F A=f(G H F, H P, G M, D A, N C, S A)$

$F A=\beta_{0}+\beta_{1} \mathrm{GHF}_{\mathrm{i}}+\beta_{2} \mathrm{HP}_{\mathrm{i}}+\beta_{3} \mathrm{GM}_{\mathrm{i}}+\beta_{4} \mathrm{DA}_{\mathrm{i}}+\beta_{5} \mathrm{NC}_{\mathrm{i}}+\beta_{6} \mathrm{SA}+\varepsilon_{\mathrm{i}}$

Where: Food Affordability (FA)

Green House Farming (GHF)

Hydroponics (HP)

Geo-Mapping (GM)

Drone Agriculture (DA)

Nutrient Cycling (NC)

Soil Analysis (SA)

The study expects that a positive and significant effect will be observed between the smart Agriprenuership dimensions and food affordability. In furtherance of this study, adherence to the ethics of research was strictly adhered to, as confidentiality, anonymity, and secrecy were utilized in the data collection process. Also, the works of other scholars were duly acknowledged.

\section{Results, InTERPRETATION \&} Discussions

Of the 632 respondents targeted, 558 respondents correctly filled out the research instrument satisfactorily, which is an $88.3 \%$ success rate. The regression analysis results which tested the effect of smart Agri-preneurship dimension son food affordability in South West Nigeria, are as presented in Table 2.

Table 2: Inferential outcome of smart Agri-preneurship onfood affordability

\begin{tabular}{|c|c|c|c|c|c|}
\hline \multicolumn{6}{|c|}{ Coefficients $^{a}$} \\
\hline \multirow{2}{*}{ Model } & \multicolumn{2}{|c|}{ Unstandardized Coefficients } & $\begin{array}{c}\text { Standardized } \\
\text { Coefficients }\end{array}$ & \multirow{2}{*}{$\mathrm{t}$} & \multirow{2}{*}{ Sig. } \\
\hline & $B$ & Std. Error & Beta & & \\
\hline (Constant) & 0.246 & 0.155 & & 1.587 & 0.113 \\
\hline Green House Farming & 0.126 & 0.049 & 0.115 & 2.540 & 0.011 \\
\hline Hydroponics & 0.204 & 0.049 & 0.202 & 4.174 & 0.000 \\
\hline Geo-Mapping & 0.134 & 0.039 & 0.142 & 3.413 & 0.001 \\
\hline Drone Agriculture & 0.029 & 0.019 & 0.044 & 1.519 & 0.129 \\
\hline Nutrient Cycling & 0.223 & 0.041 & 0.225 & 5.495 & 0.000 \\
\hline Soil Analysis & 0.216 & 0.041 & 0.217 & 5.261 & 0.000 \\
\hline $\mathrm{R}=$ & $\begin{array}{c}a . \\
g^{a} R^{2}=0.606\end{array}$ & $\begin{array}{l}\text { ndent Variab } \\
\text { dj. } R^{2}=0.602\end{array}$ & $\begin{array}{l}\text { Affordability } \\
551)=141.319\end{array}$ & & \\
\hline
\end{tabular}

Source: Field Survey (2020)

From Table 2, the multiple regression outcomes showed that smart Agri-preneurship dimensions have a positive and significant effect on food affordability in South-West Nigeria at $p<0.05$. Also, the F-statistics (df $=6,551)=141.319$ clearly indicates that the overall model is robust enough in predicting the effect of smart
Agri-preneurship dimensions on food affordability. Furthermore, the $R^{2}=0.606$ reveals that smart Agripreneurship dimensions have a moderate positive and significant effect on food affordability in South-West, Nigeria while the adjusted $R^{2}=0.602$ explained that $60.2 \%$ of the variations in food affordability is accounted 
for by smart Agri-preneurship dimensions, while the difference of $39.8 \%$ could be explained by other factors not included in this model.

Additionally, some of the measures of smart Agri-preneurship provided positive and significant effects on food affordability in South-West, Nigeria at $p<0.05$, as their respective beta-values are as follows: greenhouse farming $(\beta=0.126, t=2.540)$, hydroponics $(\beta=0.204, t=4.174)$, geo-mapping $(\beta=0.134, t=$ 3.413), nutrient cycling ( $\beta=0.223, t=5.495)$ and soil analysis $(\beta=0.216, \mathrm{t}=5.261)$. However, drone agriculture $(\beta=0.029, t=1.519)$ revealed positive but insignificant effect on food affordability in South-West, Nigeria. Based on the foregoing, the econometric model of the study is thus expressed as:

$$
\begin{array}{ll}
\mathrm{FA}=0.246+0.126 \mathrm{GHF}+0.204 \mathrm{HP}+0.134 \mathrm{GM}+0.223 \mathrm{NC}+0.216 \mathrm{SA} \\
\text { where FP = Food Affordability; } \quad \mathrm{GHF}=\text { Green House Farming; HP = Hydroponics; } \\
\mathrm{GM}=\text { Geo-Mapping; } & \mathrm{NC}=\text { Nutrient Cycling; } \mathrm{SA}=\text { Soil Analysis }
\end{array}
$$

From the regression model expressed above, when smart Agri-preneurship dimensions are at a constant zero, food affordability would be a positive value of 0.246 . Furthermore, the regression model explains further that when greenhouse farming, hydroponics, geo-mapping, nutrient cycling, and soil analysis are improved by one unit, food affordability would also increase by $0.126,0.204,0.134,0.223$ and 0.216 units respectively. This implies that an increase in smart Agri-preneurship dimensions (greenhouse farming, hydroponics, geo-mapping, nutrient cycling, and soil analysis) would lead to a subsequent increase in food affordability in South-West, Nigeria. The result of the multiple regression analysis revealed that smart Agripreneurship is pertinent in improving food affordability in South-West, Nigeria. In light of the foregoing, the study upholds the apriori expectation that there is a positive, significant effect of smart Agri-preneurship dimensions on food affordability in South-West,Nigeria.

\section{Vil. Discussions}

The findings of this study further strengthens the positions of earlier scholars such as Vox, Teitel, Pardossi, Minuto, Tinivella, and Schettini (2010), Santeramo (2015), Hubeau, Marchand, Coteur, Mondelaers, Debruyne, and Van-Huylenbroeck, (2017) and Velde and Nisini (2019) who posit that modern agribusiness and other smart Agri-preneurship measures have positively and significantly enhanced optimization of farm land, increase farm output and affordability of farm products. Also, with the outcome of various scholars (Currey, Walters, \& Flax, 2019; Zaccardelli, Pane, Villecco, Palese \& Celano, 2018; Brück, Naudé, \& Verwimp, 2011) who revealed that smart Agri-preneurship significantly reduced cost of farm produce hence improving food availability when Agri-preneruship induced innovations such as biostimulants were applied. The results of this studyis further validated of this position, especially from the view-point of nutrient cycling.

Other scholars such as Alston, Beddow, and Pardey (2009), Wiebe (2003), Barwa (2014), Clark, Rouse, Sehgal, Bailey, Bell, Pike, Sharpe and Freedman (2019), Gupta and Kaushal (2018) that empirically investigated how smart Agri-preneurship affected food affordability with measures such as agriculture output cost of production and farm productivity, posited that stress on farmers and cost of production dropped significantly, and a subsequent resultant increase in consumers' affordability of farm produce was observed. From the context of hydroponics as a measure of smart Agri-preneurship, diverse authors (Labya et al., 2018; Nisha, Somen, Kaushal, Narendra, \& Chaurasia, 2018; Sarah, 2019) found positive and significant relationship existing between hydroponic processes and food affordability, as they observed that access to water had the greatest effect on the urban hydroponic farming, which is conformity with the findings of this study. There are other studies (Zamora-Izquierdo, Santa, Martínez, Martinez, and Skarmeta (2019) and Pack and Mehta (2012), that have established empirical recognition for greenhouse technology as a key to sustainable crop production and food affordability as it serves in providing growth in farm productivity which corroborates the results of this study too.

However, a number of scholars (Dauphin, Lubroth \& Jobre, 2016; Fernando \& Merino, 2012; Wongkiew, Park, Chandran, \& Khanal, 2018) empirically refuted the trend of a positive and significant influence of smart Agri-preneurship on food affordability and provided divergence from the results of this study. Their position was strengthened by the fact that the smart Agri-preneurship process involves higher technology and as such a high capital outlay. Hence, the incremental cost of food production is passed on to the output, making the food output less affordable to the common man. Similarly, although the findings of Anderson (2014) which amplified the role of drone agriculture in enhancing geographical coverage, analysis, early pest and disease spotting on farmland and as such significantly increase farm output, overall yield performance and farm produce affordability, the position contradicts the results of this study.

Based on this outcome, the study indicates that farmers should focus on greenhouse farming, hydroponics, geo-mapping, nutrient cycling, and soil analysis to improve food affordability in South-West, Nigeria. 


\section{Vili. COnclusion}

This research sought to investigate the effect of smart Agri-preneurship dimensions on food affordability in South-West, Nigeria. The results revealed that smart Agri-preneurship dimensions provided positive and significant effect on food affordability. However, an x-ray of the smart Agri-preneurship dimensions revealed that all dimensions except drone agriculture provided a positive and significant relations with food affordability. The outcome of the study confirmed the apriori expectation of the study. The study hence concludes that smart Agri-preneurship dimensions are indeed imperative for the exponential growth in farm yield, which in turn improves the availability as well as affordability of food to the average citizen in South-West, Nigeria hence reducing starvation. The study recommends that agribusinesses should engage more proactively as there are large blue oceans in the adoption of smart Agri-preneurship in an environment where staple meals are less processed and the population growth is driving demand for food product.

The research acclaims that the government should reach out to Agri-preneurs, especially the rural dwellers, with a view on partnering with them to improve their farm productivity through smart Agri-preneurship mechanisms. Also, other smart agri-preneurial indicators not considered in this study can be investigated to confirm their influence on food affordability, preferably within the northern part of Nigeria.

\section{References Références Referencias}

1. Aatif, H., Kaiser, I., Showket, A., Prasanto, M., \& Negi A. K. (2018). A review on the science of growing crops without soil (soilless culture)-A novel alternative for growing crops. International Journal of Agriculture and Crop Sciences, 7(11), 833-842.

2. Achim, W., Robert, F., Robert, H., \& Nina B. (2017). Smart farming is key to developing sustainable agriculture. PNAS, 114(24), 6148-6150.

3. Adelowokan, O. A., Maku, O. E., Babasanya, A. O., \&Adesoye, A. B. (2019). Unemployment, poverty and economic growth in Nigeria. Journal of Economics \& Management, 35, 5- 17.

4. Al-Arab, M., Torres-Rua, A., Ticlavilca, A., Jensen, A., \& McKee, M. (2013, July). Use of high-resolution multispectral imagery from an unmanned aerial vehicle in precision agriculture. In 2013 IEEE International Geoscience and Remote Sensing Symposium-IGARSS (pp. 2852-2855). IEEE.

5. Al-Houti, F. (2017). Evaluation of the effectiveness of Supplemental lights vs No supplemental lights on hydroponically grown lettuce (Doctoral dissertation), Colorado State University Libraries.

6. Alston, J. M., Beddow, J. M., \& Pardey, P. G. (2009). Agricultural research, productivity, and food prices in the long run: A recent summary of the evidence. Journal of Agriculture Science, 325(4), 1209-1210.

7. Anderson, C. (2014). Agricultural drones. Technology Review, 117(3), 58-60.

8. Arantxa, Carlos, Guerrero, Mariana and Mishel (2018)

9. Barwa, S. L. (2014). Agri-preneurship development as a tool to upliftment of agriculture. International Journal of Scientific and Research Publication, 4(3), 1-4.

10. Browne, A. (2018). Hydroponic towering agriculture vs traditional soil farming in Southern Arizona. (A thesis), University of Arizona.

11. Brück, T., Naudé, W., \& Verwimp, P. (2011). Small business, entrepreneurship and violent conflict in developing countries. Journal of Small Business Entrepreneurship 24(2), 161-178.

12. Cains, F., \& Henshel, F. (2019). Exploiting plant volatile organic compounds (VOCs) in agriculture to improve sustainable defence strategies and productivity of crops. Frontiers in plant science, 10, 264.

13. Capone, R., Bilali, H. E., Debs, P., Cardone, G., \& Driouech, N. (2014). Food economic accessibility and affordability in the mediterranean region: An exploratory assessment at micro and macro levels. Journal of Food Security, 2(1), 1-12.

14. Chait, J. (2014). Agribusiness: About money. Retrieved from http://organic.about.com/od/org anicdefinitions/g/Agribusiness-Definition-Of-Agrib usiness.htm

15. Clapp, J., Newell, P., \& Brent, Z. W. (2018). The global political economy of climate change, agriculture and food systems. The Journal of Peasant Studies, 45(1), 80-88.

16. Clark, J. K., Rouse, C., Sehgal, A. R., Bailey, M., Bell, B. A., Pike, S. N., Sharpe, P. A., \& Freedman, D A. (2019). Food hub to address healthy food access gaps: Residents' preferences. Journal of Agriculture, Food Systems, and Community Development, 9(1), 59-68.

17. Cochran, W. D., Hatzes, A. P., Butler, R. P., \& Marcy, G. W. (1997). The discovery of a planetary companion to 16 Cygni B. The Astrophysical Journal, 483(1), 457

18. Currey, C. J., Walters, K. J., \& Flax, N. J. (2019). Nutrient solution strength does not interact with the daily light integral to affect hydroponic cilantro, dill, and parsley growth and tissue mineral nutrient concentrations. Agronomy, 9(7), 389.

19. Dauphin, G., Lubroth, J., \& Jobre, Y. M. (2016). Predominance and geo-mapping of avian influenza H5N1 in poultry sectors in Egypt. Geospatial Health, 11, 492-494.

20. David, V. N. (2016). What is agribusiness, a visual description. Amity Journal of Agribusiness, 1(1), 1-6. 
21. Drewnowski, A. (2020). Analysing the affordability of the EAT-Lancet diet. The Lancet Global Health, 8(1), e6-e7.

22. El Ghoumari, M. Y., Tantau, H. J., \& Serrano, J. (2005). Non-linear constrained MPC: Real-time implementation of greenhouse air temperature control. Computers and Electronics in Agriculture 49(3), 345-356.

23. Fasiha, F. K., Kaleem, A., Aleem, A., \& Shujjah, H. (2017). Applications of biotechnology in agriculturereview article. World Journal of Biology and Biotechnology, 1, 139-142.

24. Fasiha, F. K., Kaleem, A., Aleem, A., \& Shujjah, H. (2017). Applications of biotechnology in agriculturereview article. World Journal of Biology and Biotechnology, 1, 139-142.

25. Fernando, L. I., \& Merino, F. C. (2012). Nutrient solutions for hydroponic systems. Hydroponics-a standard methodology for plant biological researches, 1-22.

26. Gasparatos, A., Takeuchi, K., Elmqvist, T., Fukushi, K., Nagao, M., Swanepoel, F., Swilling, M., Trotter, D., \& Von Blottnitz H. (2017). Sustainability science for meeting Africa's challenges: Setting the stage. Sustain Science, 12, 635-640

27. Gates, B. (2019). Examining inequality. Goalkeepers Report from Bills and Melinda Gates foundation survey. Retrieved from https://www.gatesfoun dation.org/goalkeepers/report/2019-report?Dow nload $=$ false

28. Gordon, R. (2004). Phytoextraction of cadmium and zinc from a contaminated soil. Journal of Environmental Quality, 26(5), 1424-1430.

29. Gupta, S., \& Kaushal, R. (2018). General application of biotechnology in agriculture. ACTA Scientific Agriculture, 2(6), 12-19.

30. Hafsal, L. P. (2016). Precision agriculture with unmanned aerial vehicles for SMC estimations: Towards a more sustainable agriculture. (Master's thesis),

31. Harrell, C. (2014). Characterizing the rural opioid use environment in Kentucky using google earth: Virtual audit. Journal of Medical Internet Research 21(10), 14-23.

32. Hubeau, M., Marchand, F., Coteur, I., Mondelaers, K., Debruyne, L., Van Huylenbroeck, G. (2017). A new agri food systems sustainability approach to identify shared transformation pathways towards sustainability. Ecol Econ, 131, 52-63.

33. Kaur, J. (2017). Impact of climate change on agricultural productivity and food security resulting in poverty in India (Bachelor's thesis), Università Ca' Foscari Venezia.

34. Kibiti, J. G., \& Gitonga, A. K. (2017). Factors influencing adoption of urban hydroponic farming: A case of Meru town, Meru County, Kenya.
International Academic Journal of Information Sciences and Project Management, 2(1), 541-557.

35. Kropff, W., Pilgrim, V., \& Neate, P. (2019). Overcoming challenges to digital agribusiness startups in ACP countries. Wageningen: CTA Publishers.

36. Labya, P., Megha, A., \& Kamlesh, S., (2018). Hydroponics emerging technique of plant cultivation. International Journal of Engineering Technology Science and Research IJETSR, 5(2), 221-227.

37. Lanigan, Donnellan, Hanrahan, Paul, Shalloo, Krol, Forrestal, Farrelly, O'Brien, Ryan, Murphy, Caslin, Spink, Finnan, Boland, Upton and Richards (2018), and

38. Lauri, W., Palak, G., \& Kumiko, Y. (2018). Accessibility and affordability of healthy foods in food deserts in Africa: Policy and practice implications. Africa Public Health Review, 15(1), 11-

39. Lauri, W., Palak, G., \& Kumiko, Y. (2018). Accessibility and affordability of healthy foods in food deserts in Africa: Policy and practice implications. Africa Public Health Review, 15(1), 11-

40. Mansour, R. (2014). Food security among students at University of Wollongong. (Master's thesis), University of Wollongong.

41. Osabohien, R., Osabuohien, E., \& Urhie, E. (2018). Food security, institutional framework and technology: Examining the nexus in Nigeria using ARDL approach. Current Nutrition \& Food Science, 14(2), 154-163.

42. Pack, M., \& Mehta, K. (2012, October). Design of affordable greenhouses for East Africa. In 2012 IEEE Global Humanitarian Technology Conference 104110.

43. Paul, A. I., Amarachi, N. O., Oyedele, M. O., Odafe, M. E., \& Juliana, A. A. (2018). Factors affecting the investment climate, SMEs productivity and entrepreneurship in Nigeria. European Journal of Sustainable Development, 7(1), 182-200.

44. Pettersen, E. (2014). Soil phosphorus pools and their relation to land-use and soil physiochemical properties-A case study of an agricultural watershed in north-eastern China (Master's thesis).

45. Psirofonia, P., Samaritakis, V., Eliopoulos, P., \& Potamitis, I. (2017). Use of unmanned aerial vehicles for agricultural applications with emphasis on crop protection: Three novel case-studies. Int. J. Agric. Sci. Technol, 5, 30-39.

46. Rehman, A., \& Shaikh, S. (2014). Smart agriculture. International Journal of Communication Networks and Information Security, 32(2), 263- 270.

47. Santeramo, F. G. (2015). On the composite indicators for food security: Decisions matter! Food Reviews International, 31 (1), 63-73.

48. Sardare, M. D., \& Admane, S. V. (2015). A review on plant without soil-hydroponics. International Journal 
of Research in Engineering and Technology, 2 (03), 299-304.

49. Sayem, A. S. (2017). Agricultural drone: a greentech technology. Optics Communications, 384, 50-58.

50. Solomon, D., Mungai, C., \& Radeny, M. (2017). Climate-smart agriculture (CSA) for resilient agriculture, food security and inclusive business growth in East Africa. Retrieved from http://knowledge4food.net/wpcontent/uploads/2017 /11/171201 theme7 csa backgroun d-paper.pdf.

51. Torres, A. (2017). Drones in agriculture: an overview of current capabilities and future directions. In Utah Water Users Workshop, Saint George, UT, USA (pp. 1-9).

52. Uche, C., \&Familusi, L. (2018). The adoption of Agripreneurship as a mitigating measure to unemployment in Nigeria: A topical review. Global Journal of Business and Management Research. 18 (2), 5.

53. Velde, M. V. D., \& Nisini, L. (2019). Performance of the MARS-crop yield forecasting system for the European Union: Assessing accuracy, in-season, and year-to-year improvements from 1993 to 2015. Report from European Commission, Joint Research Centre (JRC), Ispra 21027, Italy.

54. Vox, H., Teitel, Y., Pardossi, F., Minuto, A., Tinivella, E., \& Schettini, K. (2010). Household food security in rural areas of Nepal - Relationship between socioeconomic characteristic and food security status. A Paper Presented at the International Association of Agricultural Economist Conference, Gold Coast, Australia.

55. Wekesa, B. M., Ayuya, O. I., \& Lagat, J. K. (2018). Effect of climate-smart agricultural practices on household food security in smallholder production systems: Micro-level evidence from Kenya. Agriculture and Food Security, 7(1), 86.

56. Wiebe, K. (2003). Linking land quality, agricultural productivity, and food security. Resource Economics Division, Economic Research Service, U.S. Department of Agriculture. Agricultural Economic Report No.: 823.

57. Wongkiew, S., Park, M. R., Chandran, K., \& Khanal, S. K. (2018). Aquaponic systems for sustainable resource recovery: Linking nitrogen transformations to microbial communities. Environmental Science \& Technology, 52(21), 12728-12739.

58. World Population Prospect (WPP) (2019). Prepared by population division of the department of economic and social affairs of the United Nations secretariat. Retrieved from https://populat ion.un.org/wpp/

59. Wright, L., Gupta, P., \& Yoshihara, K. (2018). Accessibility and Affordability of Healthy Foods in Food Deserts in Florida: Policy and Practice Implications. Florida Public Health Review, 15(1), 11.
60. Yi-Hsuan, H., Ssu-Pei, L., \& Ting, L. (2019). The application of organic hydroponics on homegrown urban agriculture in Taiwan comma company. (Unpublished thesis). National Chiayi University, Taiwan.

61. Yliskylä-Peuralahti, J. (2014). Binding rules or voluntary actions? A conceptual framework for CSR in shipping. WMU Journal of Maritime Affairs, 13(2), 251-268.

62. Zaccardelli, M., Pane, C., Villecco, D., Palese, A. M., \& Celano, G. (2018). Compost tea spraying increases yield performance of pepper (Capsicum annuum L.) grown in greenhouse under organic farming system. Italian Journal of Agronomy, 13(3), 229-234.

63. Zamora-Izquierdo, M. A., Santa, J., Martínez, J. A., Martínez, V., \& Skarmeta, A. F. (2019). Smart farming loT platform based on edge and cloud computing. Biosystems engineering, 177, 4-17.

64. Zikmund, W. G., Babin, B. J., Carr, J. C., \& Griffin, M. (2010). Business research methods (8th ed.). New York: South-Western. 